\title{
A Contribution to the Definition of Thermal Belt in Sub-pannonian Slovenia
}

Ogrin, Darko'

\begin{abstract}
The paper presents how the method of determining spatial characteristics of thermal belt by means of an accurate mapping of vineyards can be applied. Analyses were carried out in three areas, one in the north, one in the central and one in the south part of the Pannonian margin of Slovenia. The results have proved the method to be an adequate means for climatic investigations on a local level, where we often lack a sufficient network of meteorological stations, so that we also have to use indirect methods to obtain climatic information. However, the results have also pointed out some of the method's limitations. It is useful particularly for the regions where the tradition of viniculture has been very long and the population has acquired apt knowledge about the local climatic conditions related to vine. It gives good results in the regions with varied landforms and sufficiently explicit vertical zoning. The results obtained show the spatial characteristics of thermal belt mainly at the beginning of the vegetation period of vine in spring, when it is most sensitive to frost. In addition to insolation, frost hazard is the most important climatic factor for the location of vineyards.
\end{abstract}

Key words: Behaviourism, Local climate, Sub-Pannonian Slovenia, Thermal belt, Topoclimate, Vertical climatic zoning and Vineyards mapping

\footnotetext{
1 Darko Ogrin

Department of Geography

Faculty of Arts, University of Ljubljana Aškerčeva 2, SI-1000 Ljubljana, Slovenia darko.ogrin@ff.uni-lj.si
}

\section{Introduction}

In Slovenian geography, the first to deal with the climatic zoning, and within its framework with the definition and the extent of thermal belt, was Gams (1972). He comprehends it as a belt lying above the bottom of basins, valleys and karst depressions, in which temperature inversion with lakes of cold air develops during the anticyclonic type of weather and, consequently, it is warmer than the inversion belt. It is likewise warmer than the higher-lying areas above it, where the air temperature drops due to the higher altitude above sea level. Especially the minimum temperatures (absolute and mean) are higher in thermal belt, which is of great importance in agriculture for the growing of thermally more demanding cultures. Due to lesser frost hazard, in the hilly Pannonian margin of Slovenia, for example, practically all the vineyards and most of the orchards lie on the sunny slopes in the thermal belt, while in Mediterranean Slovenia olive grooves are situated at such locations.

By means of comparison of the data from meteorological stations at the bottom of the valleys (basins) with those from the nearby slopes in the thermal belt, Gams (1996) established that the mean minimum temperatures were approximately by $2^{\circ} \mathrm{C}$ higher at the stations in the thermal belt in Slovenia. A comparison made for the Pomurje region in the Pannonian part of Slovenia has shown that places at the bottom of the valleys are frost-free only for three months per year, while places some 150 meters above the valley bottoms are frost-free as many as six months.

The exact determination of the lower and upper limits of thermal belt seems to be a special problem. This is important from the aspect of climatology in determining the topoclimatic units and in topoclimatic mapping for example, and from the application aspect, in the planning of the cultural landscape use, e.g. in agriculture and settling. It is practically impossible to determine the extent of the thermal belt in individual Slovenian regions by means of multi-year average of climatic data because of the insufficient network of meteorological stations. We can only determine for orientation the upper limit for the whole of Slovenia by means of such data. The mean minimum temperatures indicate it at about 500 meters of relative height, and the mean annual temperatures at about 200-250 meters above valley bottoms (Gams, 1996; Žiberna, 1999; Ogrin, 200o).

In topoclimatic divisions and topoclimatic mapping an alternative method of determining the span of thermal belt is offered by profile measurements of minimum temperatures at certain weather situations and by a detailed mapping of growing areas of thermally demanding cultures, such as grapevine and olive tree. Namely, a comparison of the results of profile measurements of minimum temperatures during anticyclonic weather with the spatial distribution of vineyards and olive grooves in test areas shows a close correspondence of the extent of the thermal belt as established by means of the two methods. Vineyards indicate the lower limit of thermal belt at between 15 and 30 meters above valley bottoms and the upper limit at about 450-550 meters above sea level (Žiberna, 1992), and olive trees at between 10 and 40 meters above valley bottoms, and at about 250 , rarely 300 meters above sea level, respectively (Ogrin and Mužina, 2005).

Proceeding from earlier results and advice in expert literature (e.g. Geiger, 1966) that in case of insufficient data from meteorological stations we can get an insight into the basic climatic structure of a certain region also by analysing the modifiers that influence the climatic features and by observing specific features of natural vegetation and cultural landscape use, we tried to determine the extent and characteristics of thermal belt in the Pannonian part of Slovenia by means of mapping the vineyard areas. The coline belt at the margin of the Pannonian basin in Slovenia is an important wine-growing region in the country. The tradition of viniculture reaches back into the time of the Roman Empire, therefore our presumption was that in the course of the millennium of tradition 

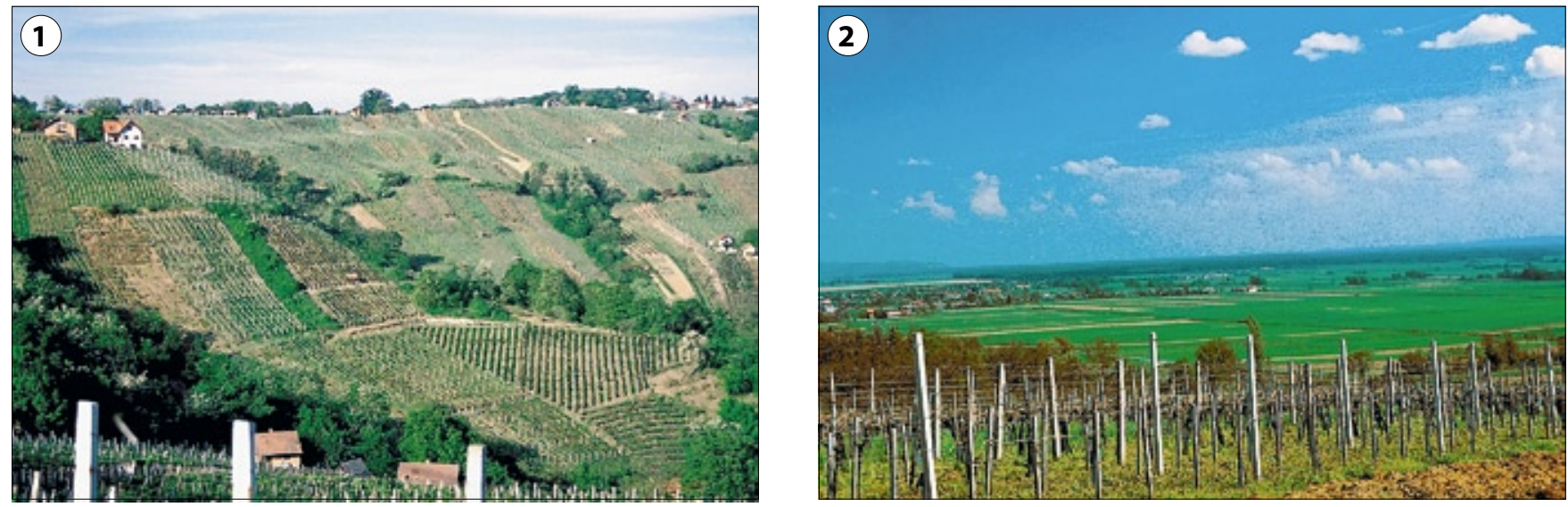

Figure 1 Hilly and level types of landscapes in sub-Pannonian Slovenia in the case of Lendavske gorice (1) and Dolinsko (2) in Prekmurje region (NE Slovenia); photo: D. Ogrin.

people had acquired sufficient knowledge about the optimum locations for grapevine, where frost hazard was the least and the climatic conditions for the growth and ripening of grapes were the best.

\section{Presentation of the researched area and theoretical-metodological bases}

The Pannonian part of Slovenia lies in the westernmost end of the Pannonian lowland, i.e., at its transition into the Dinaric karst and the undulated foothills of the Alps. Due to the passable territory and the intertwining of Pannonian features with the karstic and the sub-Alpine ones, the term of sub-Pannonian landscapes has been established for them in Slovenian geography. They are typical for level world along the bigger rivers (the Mura, Drava, Sava, Krka) and on the karst plain of Bela Krajina, with undulated areas in between (Figure 1). Except for Bela krajina, which mainly consists of limestone and is therefore ranked among the Dinaric karst regions in some physico-geographical divisions of Slovenia, the remaining plains are covered with deep alluvia of gravel, sand and clay. The hills consist of tertiary sediments (marl, sand, sandstone) and they are intensely dissected. Typical are long ridges with valleys in between. The sub-Pannonian part of Slovenia has the most explicit features of continental climate, with the highest temperature amplitudes and the smallest precipitation amount. The water network is dense because of the prevailing impermeable basis. Thanks to favourable natural conditions and quality soils, dense agrarian settling and intense agriculture are typical. Typical of plains are long roadside villages and explicit predominance of agrarian areas, mainly fields and meadows. The hills are settled on tops in the form of dispersed settlements. Owing to favourable insolation, position above the inversion air layer and lesser frost hazard, vineyards and orchards are located on the sunny slopes of the hills, and forest prevails on the shady slopes.
In order to determine the features of thermal belt by means of mapping the vineyards in the hills of sub-Pannonian Slovenia we selected three investigation areas: Goričko in the north, Posotelje in the central part, and Bela Krajina in the south (Figure 2). It was a direct fieldwork mapping; the vineyard areas were marked in a topographic map at the scale of 1:500o. We were particularly careful with the upper and lower limits of vineyards and with the height of the lower limit above the bottoms of the valleys. Proceeding from our conviction that local people were fully familiar with local climatic conditions and that they applied their knowledge in practice, we proposed a thesis that the lower and the upper height limits of vineyards determine

frost hazards. We were particularly interested in the criteria applied for the location of new vineyards.

In interpreting the results obtained by mapping and interviews we were aware of the fact that the acting of people more of ten depended on their perception of landscape and its characteristics (even of climate) than on the actual situation, and that, in addition to the information about what actually existed in the landscape, people also provided us, through their mental transformation of the information about the landscape, with their own attitude towards it. In fact, with this phase of investigation we touched upon behavioristic geography, which developed in geography and other sciences in the 1960 s as an

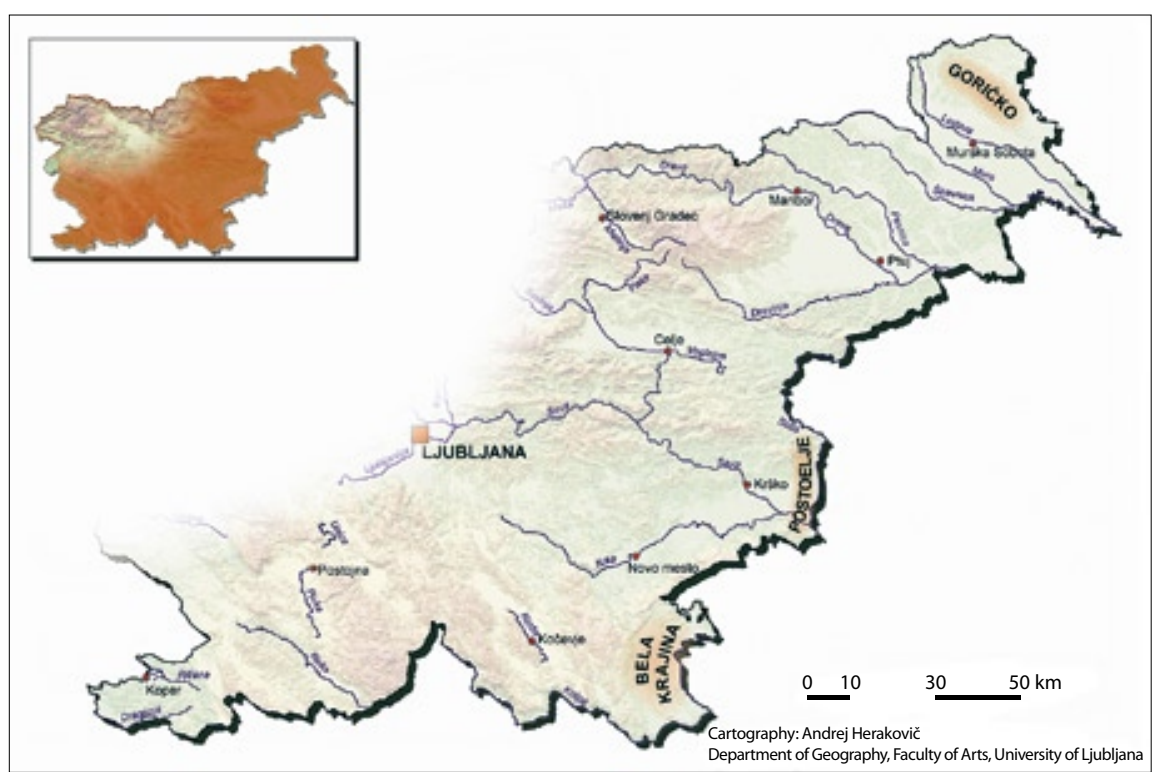

Figure 2 Geographical position of the researched area

the thermal belt (the area of lesser frost hazard), and that the lower limit is also the average height reached by lakes of cold air in the warm half of the year or at the beginning of the vegetation season of grapevine, when it is most sensitive to frost. Our fieldwork also included interviews with the locals. We questioned them about the local weather- and climate characteristics, particularly about white-frost and general opposition to the then completely prevailing positivism (Kaplan et al., 2004). Behavioristic geography believes that humans are not machines that would respond to impulses from the external world always in the same way, but rather their reactions that recreate the landscape through the activity are the result of the relationship between individuals and their environment. Thus, human activity is exclusively the re- 
sult of their response to the mental image they have created in their mind, and not of their response to the actual situation, since only one landscape exists for an individual, i.e. the perceived landscape (Johnston et al., 2003). Proceeding from this is the fact that people behave rationally within the scope of their own knowledge and comprehension of landscape situation, yet the perceived environment is not the same as the factual environment or the one as comprehended by a researcher. People make different decisions related to their environment, but these decisions are often learned and proceed from the customs and recurring decisions. In our case it means that the assessment of thermal belt as reached by means of vineyard mapping mainly results from the tradition and repeated attempts of several generations to find the optimum position for vine. As such, it definitely does not coincide with the thermal belt that would be assessed in a certain landscape by means of empirical investigations, and its spatial characteristics may vary from place to place, not necessarily as the result of the circumstances in a landscape, but rather because of the differences in the perception of landscape reality (also of climate) by the local people.

For an easier evaluation of the results obtained in this way we also performed several profile measurements in the researched areas of minimum temperatures during the anticyclonic weather. In such a way we got the information about the extent, intensity and spatial characteristics of inversion and inversion belt and of the thermal belt above the latter during certain weather situations. We concentrated on the measurements in the warm half of the year, when the inversion and its resultant minimum temperatures and spring frosts are important for cultural plants. Along the selected profiles running from the bottom of the valleys (plains) up to the top of the hills, temperatures at 20 to 40 representative sites, depending on the length of the profile, were measured with a digital thermometer fixed to a car which was moving with a constant speed of $40 \mathrm{~km} /$ hour. Measurements were performed just before the sunrise when temperatures are the lowest.

\section{Thermal belt as indicated by vineyards}

\section{Thermal belt in Bela Krajina}

Vineyard areas in Bela Krajina were mapped at 34 locations. Treated separately were dispersed vineyards on hums on the plain and in the valley of the Kolpa, and also the vineyards on the elevated edge from Poljanska Gora to the Gorjanci range, which are distributed in a more or less continuous belt. Vineyards on hums mainly begin at about 10 meters above the level of the karstic plain, and quite often they reach down to the plain itself. It was problematic to determine the lower limit because of the highly varied surface with numerous sinkholes and other more or less expressed basins. In the valley of the Kolpa, the lower limit of vineyards runs higher above the bottom of the valley, i.e. from 25 to 80 meters. This is probably the result of lesser insolation at the bottom, due to a higher horizon and higher humidity of the air, which does not suit the vine because of a greater disease hazard. The upper height lim- series. The first one was performed in the area between the valley of the Kolpa and the top of the vineyard hum in the centre of the plain, and the second one was performed in the area across the plain to the hilly circumference. Typical of the first series (6 May 2002; from 05:39 to 06:03), from the valley of the Kolpa near Pobrežje (150 meters above sea level) to the top of Velika Plešivica (363 meters a.s.l.), was shallow in version. The lowest temperatures, between 7.3 and $8^{\circ} \mathrm{C}$, were measured in shallow de-

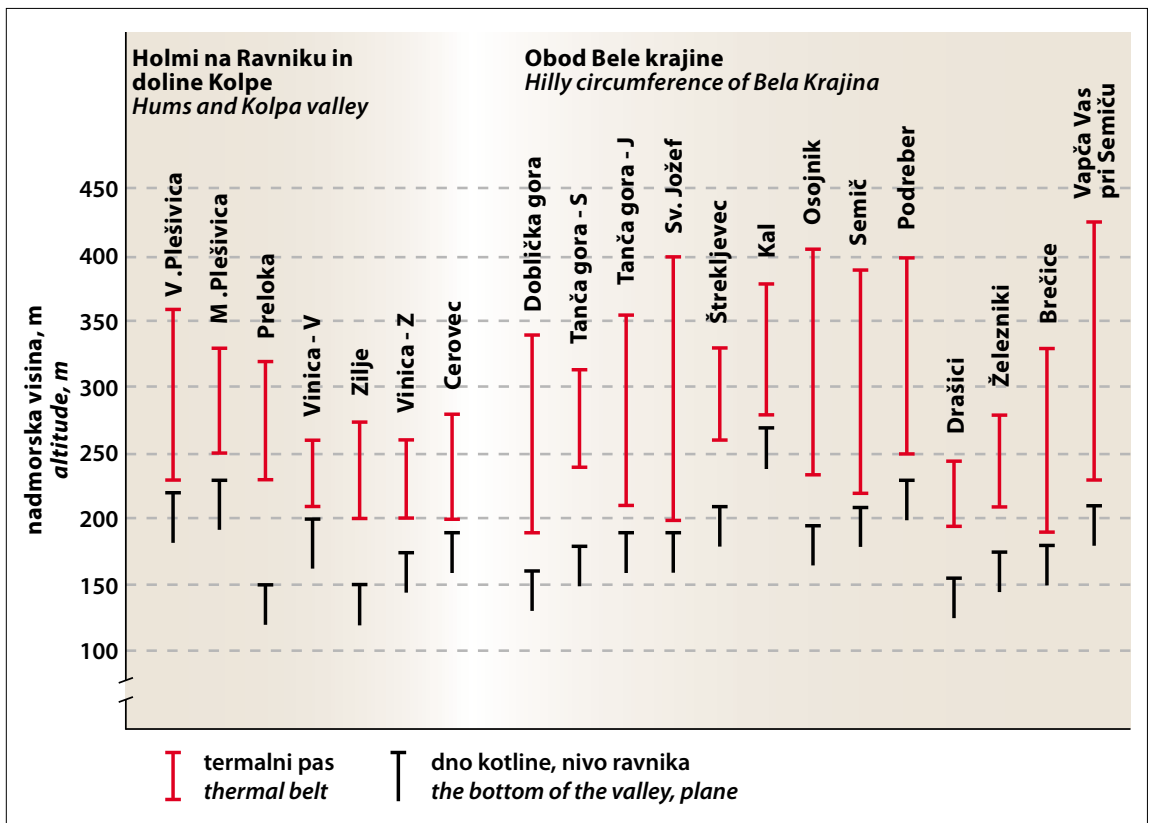

Figure 3 Thermal belt in Bela Krajina (SE Slovenia) as indicated by vineyards

it, up to which vineyards reach, lies between 260 and 360 meters and it mainly depends on the height of hums and slopes above the Kolpa. More than a half of the mapped vineyards $(58 \%)$ are south-oriented, next come SW (34\%) and SE (8\%) positions.

The lower and upper limits of vineyards on the hilly circumference of Bela Krajina are more clearly expressed. These vineyards mainly begin at 10 to 40 meters above the level of the plain (190 to 250 meters above sea level) and reach up the slopes to the maximum of 200 meters of relative height (i.e. up to approx. 425 meters above sea level). The vertical span of the vineyard belt is from 50 meters near Drašiči, up to 200 meters near Semič. Because of the orientation of the slopes along the edge of Bela Krajina, the distribution of vineyards is slightly different from those on the plain. Most of them have SE position (45\%), next come south (28\%), SW (14\%) and east ( $9 \%$ ) positions.

The thermal belt as indicated by vineyards corresponds neatly with the findings attained by means of the measurements of minimum temperatures during anticyclonic weather in the warm half of the year. In the 2001-2004 period, nine measurement series were performed along different profiles. Presented on the following pages are the results of the two most representative pressions (sinkholes) in the plain. Temperatures along the Kolpa were slightly higher, 8 to $8.5^{\circ} \mathrm{C}$, while on Plešivica they were between 10 and $12.5^{\circ} \mathrm{C}$, i.e. by 2 to 5 degrees higher than in the plain. Shallow lakes of cold air, 5 to 10 meters deep, were also indicated by mist in the valley of the Kolpa and in the depressions in the plain.

Similar characteristics were also registered at the inversion of 12 May 2002, between 05:18 and 05:57, when temperatures were measured from Marindol (220 meters a.s.l.) to Vrčice above Semič ( 480 meters a.s.l.). Temperatures in the plain were between 9 and $12^{\circ} \mathrm{C}$, the highest were on the rim at the altitude between 230 and 400 meters (between 12 and $16^{\circ} \mathrm{C}$ ), then they gradually dropped parallel to the increasing altitude. These measurements point to a thermal belt lying between 230 and 400 meters a.s.l. Below the thermal belt, there was a 10-to-30-meter deep lake of cold air (inversion area), and a coline belt above it, which is clearly evident also from the measurements of 19 August 2003 (Figure 4).

Proceeding from the above-presented and other measurements done in Bela Krajina we conclude that shallow inversions, which dissolve soon after the sunrise, are typical of the warm half of the year, when nights are short and the conditions for the 
air to cool are poorer. The temperatures in the valley of the Kolpa and in the depressions in the plain are lower by 4 to $6.5^{\circ} \mathrm{C}$ than those in the thermal belt. The vertical span of the latter is broader in the warm half of the year; it begins at 5 to 10 meters above the level of the plain and reaches up to about 350 meters of relative height. However, thermal belt on the hilly circumference of Bela Krajina is not the warmest, since from the slopes of the higher coline belt above it cold air descends to lower areas. Established as the warmest were the higher isolated hums in the plain, which reach above the inversion layer of cooler air in the warm half of the year. Therefore it is not surprising that, like the thermal belt on the edge, some hums, too, are explicit winegrowing areas, and that in some gardens fig trees also grow (a typical cultural plant of the Mediterranean), which, according to the locals, are never completely damaged by frost.

According to the above-presented measurements, thermal belt in Bela Krajina is supposed to reach up to 350 meters of relative height in the warm half of the year, but vineyards indicate that its upper limit is lower, at 200 meters of relative height at the most, which is up to 425 meters above sea level. The reason why vineyards do not reach up to higher altitudes lies in the fact that in many a place landforms are too steep. When asked what the main criteria for locating new vineyards were, the majority of the locals named experiences and oral tradition ("Our elders knew very well, where frost hazard was the least and where the vineyards were best oriented towards the sun."), or abandoned vineyards that had already been at the selected locations in the past. However, we could not get precise answers to the question of how deep down into the valley a vineyard could reach. We were told that it was not reasonable to plant vine too close to the bottom, because it was over-exposed to damages by frost there. We actually got the most precise answer from an elderly local who explained that vine below the village towards the Kolpa was planted "to the horizon", which means up to the level of the karst plain on the Croatian bank of the river, that is about 40 meters above the bottom of the valley.

\section{Thermal belt in Posotelje}

Vineyards in Posotelje were mapped at 6 locations in the surroundings of Imeno and Virštajn. This is a marked vinicultural area with vineyards on the sunny sides of the hills. Vineyards begin at about 40 meters above the bottom of the valley of the Sotla and the brook of Globinjski potok, and reach up to the highest tops of the hills, i.e. over 400 meters above sea level (Table 1). In Posotelje it was only possible to establish the lower limit of thermal belt by means of vineyards locations; it mainly starts at 30 to 40 meters above the bottom of the valleys.

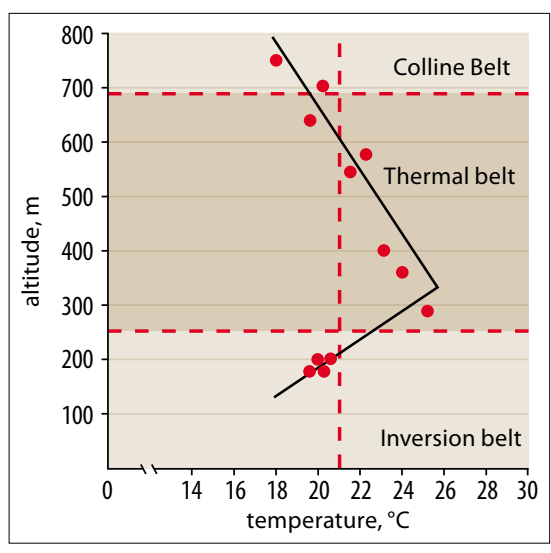

Figure 4 Minimum temperatures during anticyclonic weather in Bela Krajina along the profile from Črnomelj (160 meters a.s.l.) to Planina pod Mirno Goro (720 meters a.s.l.) (19 August 2003; 04:30-05:05)

But because of the low height of landforms it was not possible to establish its upper limit and the vertical span of the thermal belt, since grapevine would be planted even higher should the landforms permit. This is corroborated by examples from other, i.e. higher, hills of sub-Pannonian Slovenia, where grapevine grows even at altitudes higher than 500 meters above sea level.

Vineyards in Central Posotelje indicate the average depth of inversion air layer to be between 30 and 40 meters. Like in the case of Bela Krajina, we tried to test read between o and $5.5^{\circ} \mathrm{C}$. The differences between the coldest and the warmest areas were $7.3^{\circ} \mathrm{C}$ on 7 March $2000 ; 10.4^{\circ} \mathrm{C}$ on 8 March 2000; and $6.7^{\circ} \mathrm{C}$ on 13 March 2000. The measurements point to a typical inversion situation, with the increase in temperatures parallel to the growing height above sea level. The vertical temperature lapse rate was quite high $\left(+7\right.$ to $\left.8^{\circ} \mathrm{C} / 100 \mathrm{~m}\right)$, since the vertical drop between the top of the hills and the bottom of the valleys was only 150 to 200 meters. If the isotherm of $0^{\circ} \mathrm{C}$ is taken as the upper limit of the inversion belt and the lower limit of the thermal belt, we can conclude that in the time of our measurements the thermal belt began at 50 to 70 meters above the bottom of the valleys, which is higher than the lower limit as indicated by vineyards. Nevertheless, the result is not surprising, since the measurements were done in March, when, due to favourable conditions for the cooling of the air at night, lakes of cold air were mainly deeper.

The people of Posotelje are well acquainted with local climatic differences and with greater frost hazard in the valleys. The height of mist serves them as an orientation level up to which this hazard is greater. They directly connect mist with frosts: "Frosts do not occur in our village, because mist hovers in the lower-lying valleys. We are not afraid of frost, since tongues of mist never reach us." Their explanation is basically correct, since most of the frosts are

Table 1. Hypsometric characteristics of vineyards in Central Posotelje (E Slovenia)

\begin{tabular}{|l|c|c|c|c|c|}
\hline $\begin{array}{l}\text { Mapping } \\
\text { location }\end{array}$ & $\begin{array}{c}\text { Upper } \\
\text { limit of } \\
\text { vineyards }\end{array}$ & $\begin{array}{c}\text { Lower } \\
\text { limit of } \\
\text { vineyards }\end{array}$ & $\begin{array}{c}\text { Vertical } \\
\text { extent of } \\
\text { vineyards }\end{array}$ & $\begin{array}{c}\text { Altitude } \\
\text { above sea } \\
\text { level of the } \\
\text { valley bottom }\end{array}$ & $\begin{array}{c}\text { Relative height of } \\
\text { the lower limit of } \\
\text { vineyards above } \\
\text { the valley bottom }\end{array}$ \\
\hline Virštajn & $438 \mathrm{~m}$ & $250 \mathrm{~m}$ & $188 \mathrm{~m}$ & $215 \mathrm{~m}$ & $35 \mathrm{~m}$ \\
\hline Plohov breg & $376 \mathrm{~m}$ & $260 \mathrm{~m}$ & $116 \mathrm{~m}$ & $210 \mathrm{~m}$ & $50 \mathrm{~m}$ \\
\hline Kristan vrh & $381 \mathrm{~m}$ & $240 \mathrm{~m}$ & $141 \mathrm{~m}$ & $200 \mathrm{~m}$ & $40 \mathrm{~m}$ \\
\hline Imenska gorca & $355 \mathrm{~m}$ & $250 \mathrm{~m}$ & $105 \mathrm{~m}$ & $210 \mathrm{~m}$ & $40 \mathrm{~m}$ \\
\hline Imeno & $258 \mathrm{~m}$ & $230 \mathrm{~m}$ & $28 \mathrm{~m}$ & $195 \mathrm{~m}$ & $35 \mathrm{~m}$ \\
\hline Sela & $272 \mathrm{~m}$ & $230 \mathrm{~m}$ & $42 \mathrm{~m}$ & $195 \mathrm{~m}$ & $25 \mathrm{~m}$ \\
\hline Average & $280 \mathrm{~m}$ & $240 \mathrm{~m}$ & $103 \mathrm{~m}$ & $204 \mathrm{~m}$ & $37 \mathrm{~m}$ \\
\hline
\end{tabular}

the finding also by means of profile measurements of minimum temperatures during anticyclonic weather. In March 2000, three series of measurements were performed. Each time, measurements at 58 spots were made in the surroundings of Virštajn, Imeno and Podčetrtek, from the bottom of the valleys upward the slopes to the top of the hills. We selected the terms when frost was expected.

The results of the three measurement series were similar. The lowest temperatures, from -5.5 to $-3^{\circ} \mathrm{C}$, were measured at the very bottom of the valleys. At the transition of the valleys into the hills and in the lower section of the hills temperatures ranged from -3 to $0^{\circ} \mathrm{C}$, and up to this height frost occurred. In the upper section of the hills and at the top of the hills, measurements radiation-caused; they occur owing to the radiation cooling of the surface and of the ground air layer. The same process also brings about the mist, if only the air is humid enough and it cools down below the dew temperature. One of our interviewees also explained why they do not plant vine down to the very bottom of the valley: "Mist sometimes also rises from the bottom of the valley up to Vinica, hence the first rows of vineyards are some tens of meters above the bottom." And they say about the duration of frost hazard in spring: "If frost has not occurred by St. Sophie's day (15 May; author's note), it will not occur at all."

\section{Thermal belt in Goričko}

In Goričko, where vineyards were mapped at 34 locations in the east part of the hills, 


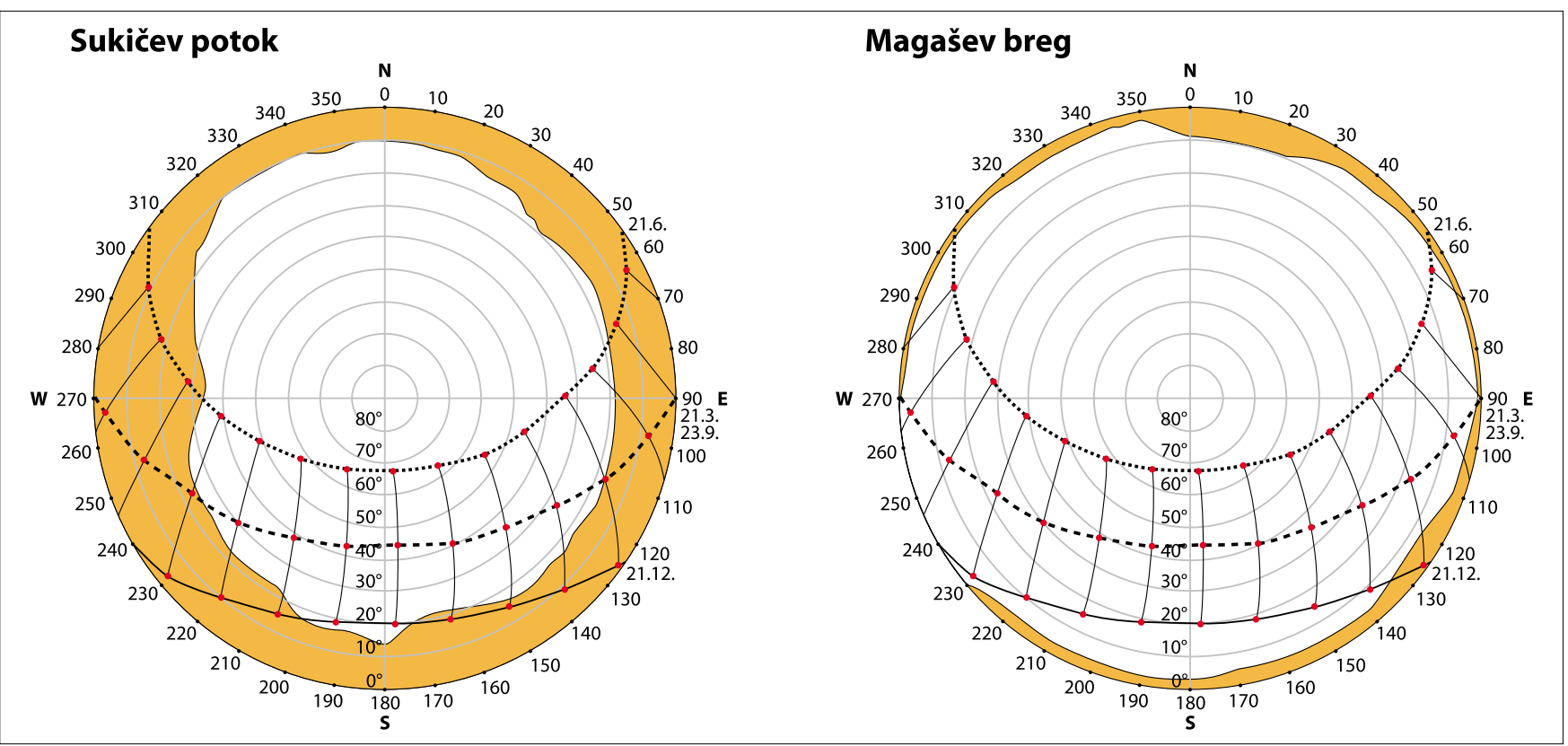

Figure $\mathbf{5}$ The course of the real horizon and the duration of insolation on the top of the hill (Magašev breg) and in the bottom of the valley (Sukičev potok) in Goričko (NE Slovenia).

the situation is somewhat specific. Vineyards reach up to the highest tops of the hills, i.e. 300 to 350 meters above sea level, or, owing to favourable landforms and climatic conditions, they are even more often located on broad tops of the hills than on sunny slopes. In addition to their position above the inversion air layer, the tops of the hills receive quite a lot of insolation, since the horizon is wide open and there are no landform barriers to shorten its time. It should be emphasized that due to the rather unvarying landforms of only little relative vertical drops, the insolation duration is favourable also in the valleys. In wintertime, when the sun is low above the horizon, the insolation in deeper valleys is shorter, due to higher horizon, by up to 3 hours than it is theoretically possible, and in summertime up to one hour at the most (Figure 5). The lower limit of vineyards in Goričko is higher than those in Bela Krajina and Posotelje, i.e. from 50 to 150 meters above the bottom of the valleys. Because of low altitudes (above sea level) of the hills, the vertical span of vineyards is rather small, from 25 to maximum of 100 meters.

Due to the low heights above sea level and only slightly varying landforms, the thermal belt in Goričko established by means of vineyards is unreliable. Vineyards do not occur at the very bottom of mainly shallow valleys, because - according to one of our interviewees - "it is thus possible to avoid frosts which damaged the cherry trees in the valleys this year (in spring of 2005; authort's note)". In spite of more favourable temperature conditions they are not even located in a greater number on the slopes, but they are concentrated on the tops of the hills, due to more favourable landforms and insolation conditions.

\section{Conclusion}

General characteristics of the thermal belt in Slovenia, whose landforms are considerably varying, are well known. Though, it often proves to be difficult to define the thermal belt and to establish its features on a local level, e.g. at topoclimatic mapping and topoclimatic divisions. Since the network of official meteorological stations is usually not dense enough for the purpose of studies at this level and the available measurements are insufficient, various indirect methods of establishing climatic features prove to be useful. One of these is the mapping of climatically demanding plants and cultures, to which grapevine also belongs.

The results presented in the paper mainly corroborate earlier findings, that by means of vineyards distribution it is possible to determine the main spatial characteristics of thermal belt as one of the elements of climatic structure of a landscape. However, this method has its specificities and limitations proceeding also from the characteristics of behavioristic approach. It is applicable mainly in the areas with centuries, or even a millennium, of unbroken continuity of viniculture and where the stage of experimenting with the search for the optimum position for this culture has already been gone by. It gives good results in the varying landforms with sufficient vertical drops, where vertical climatic belts occur and the resultant particularities in the cultural landscape use are well expressed. The most suitable in our case proved to be the hilly circumference of Bela Krajina. In determining thermal belt by means of vineyards mapping it is necessary to keep in mind that the thermal belt determined in such a way, and in relation to it also other vertical cli- matic belts, mainly stands for the climatic conditions at the beginning of the vegetation period of grapevine, i.e. at the end of April and in May, when vine is most sensitive to frost hazard. This fact is also evident from the answers given by the locals and the measurements of minimum temperatures, which prove that the vertical span of thermal belt in summertime is often greater than the one indicated by vineyards, while it is smaller in wintertime due to explicit inversions with deep lakes of cold air.

\section{References}

Gams, I. 1972. Prispevek h klimatogeografski delitvi Slovenije. Geografski obzornik 19, 1-9.

Gams, I. 1996. Termalni pas v Sloveniji. Geografski vestnik 68, 5-38.

Geiger, R. 1966. The climate near the ground. Cambridge, p. 1-611.

Johnston, R., D. Gregory, G. Pratt, M. Watts, 2003. The Dictionary of Human Geography. Blackwell, Oxford.

Kaplan, D.H., Wheeler, J.O., Holloway, S.R. 2004. Urban Geography. Arnold, London.

Ogrin, D. 200o. Nekatere topoklimatske značilnosti razporejanja temperature zraka in burje $\mathrm{v}$ razgibanem reliefu Slovenije. Dela 15, 125-138.

Ogrin, D., Mužina, D. 2005. Pokrajinskoekološke značilnosti območja med Kavčičem in Tinjanom. In: Meje in konfini (ed.: V. Rožac Darovec), Koper, pp. 289-332.

Žiberna, I. 1992. Vpliv klime na lego in razširjenost vinogradov na primeru srednjih Slovenskih goric. Geografski zbornik 32, 50-139.

Žiberna, I. 1999. Temperaturni obrat v hriboviti Sloveniji. Dela 13, 237-248. 